У,

ББК 66.2

DOI 10.22394/1682-2358-2017-4-44-52

A.V. Latkov, Doctor of Sciences (Economics), Candidate of Sciences (Politics), Professor of the Economic Civil Service Sociology Department, Povolzbsky Institute of Management named after P.A. Stolypin, Branch of the Russian Presidential Academy of National Economy and Public Administration

V.G. Oykin, Candidate of Sciences (Economics), deputy of the Saratov City Duma

\section{DYNAMICS \\ OF DUOPOLY \\ POLITICAL MARKETS \\ IN WESTERN \\ EUROPEAN \\ COUNTRIES: \\ MEASUREMENT \\ PROBLEMS}

It is suggested to use Herfindahl Hirschman index to measure the concentration of national party political systems. Based on the analysis of the index values dynamics, it is concluded that the crisis of duopoly political markets continues in Western Europe countries.

Key words and word-combinations: political market, duopoly, Herfindahl - Hirschman index.
A.B. МаткоВ, доктор экономических наук, кандидат политических наук, профессор кафедри экономической психологии и психологии государственной служби Поволжского института управления имени П.А. Стольтпина - филиала Российской академии народного хозяйства и государственной служби при Президенте РФ (email: latcov-av@yandex.ru)

В.Г. Ойкин, кандидат экономических наук, депутат Саратовской городской Аумь (email:V.Oykin@oao-oke.ru)

\section{АИНАМИКА АУОПОАЬНЫХ ПОАИТИЧЕСКИХ РЫНКОВ В ГОСУААРСТВАХ ЗАПААНОЙ ЕВРОПЫ: ПРОБАЕМЫ ИЗМЕРЕНИЯ}

Аннотация. Для измерения степени концентрации национальных партийно-политических систем предложено использовать индекс Херфиндаля - Хиршмана. На основе анализа динамики значений индекса сделан вывод о продолжении кризиса дуопольных политических рынков в государствах Западной Европы.

Ключевые слова и словосочетания: политический рынок, дуополия, индекс Херфиндаля - Хиршмана.

B торая половина XX в. Аля многих госуАарств ЗапаАной Европы характеризовацись формирование и консолидацией Авухпартийных (как вариант - Авухкоалиционных) систем в соответствующих политических пространствах. Отечественные политологи отмечают, что в конце XX - первые годы XXI в. указанные системы доминироваци в

44 Bulletin of the Volga Region Institute of Administration • 2017. Vol. 17. № 4 
Западной Европе [1]. По нашему мнению, данный тезис нуждается в уточнении. В классическом виде Авухпартийная система существует Аишь в нескольких государствах современного мира (США, Ямайка, Мамьта, с некоторой Аолей условности - Великобритания). В большинстве государств Западной Европы, скорее, наблюдается тенденция к двухпартийности, которая выражается в доминировании Авух больших политических партий или относительно устойчивых партийных коалиџий, представители которых сменяют Аруг Аруга на посту главы правительства.

Опираясь на конџепџию политического рынка, считаем џелесообразным провести аналогию между Авухпартийными системами и рынками дуопольной конкуренции. Следует отметить, что попытки распространения общепринятой в экономической теории типологии рыночных структур на различные партийные системы предпринимались и ранее [2]. Полагаем, что рассматривать динамику таких рынков можно при помощи показатемя степени концентрации, который традиџионно применяется при анализе рынков экономических благ. Таким показателем является индекс Херфиндамя - Хиршмана (Herfindahl - Hirschman index, HНI), который характеризует распределение «рыночной власти» между всеми субъектами определенного рынка и рассчитывается по следующей формуле:

$$
H H I=S_{1}^{2}+S_{2}^{2}+\ldots+S_{n}^{2},
$$

где $S_{1}-$ удельный вес на рынке самого крупного субъекта; $S_{2}-$ удельный вес следующего по величине субъекта; $S_{n}$ - удельный вес наименьшего субъекта.

Максимальное значение индекса 10000 означает, что рынок характеризуется абсолютной монополией (один субъект занимает $100 \%$ рынка).

Применительно к политическим рынкам индекс можно рассчитывать следующим образом: а) исходя из удельного веса голосов избирателей, проголосовавших за соответствующие политические партии (ици коалищии партий); б) исходя из удельного веса депутатов от политических партий (или от их коалиций) в представительном органе власти. В нашем случае исходим из первого варианта подсчета индекса, поскольку очевидно, что он учитывает более широкий круг участников избирательного проџесса. Возможные отклонения рассчитанных значений объясняются недостаточной полнотой доступных материалов о результатах парламентских выборов в соответствующих государствах. Аیя анализа были выбраны шесть западноевропейских государств: Великобритания, Австрия, ФРГ, Ирландия, Испания, Греция. Такой выбор обусловлен тем, что именно в этих государствах во второй половине XX в. наиболее отчетливо прослеживалась тенденция к двухпартийной системе (Ауопольному политическому рынку).

Аля более полного анализа динамики дуопольных политических рынков сопоставмялась динамика рассчитанных значений ННІ с Аинамикой суммарного удельного веса избирателей, проголосовавших на парламентских выборах за партии-гегемоны и суммарного удельного веса представитемей партий-гегемонов в нижних палатах наџиональных парламентов. Расчеты производицись на 
основе базы данных «Parties and Elections in Europe», которая содержит результаты выборов в законодательные органы более чем 100 европейских стран и автономных районов за период с 1945 г. Ао настояшего времени (URL: http://www.parties-and-elections.eu/).

Наиболее типичным примером бипартизма в Западной Европе считается политическая система Великобритании. В этой стране после Второй мировой войны роль второго дуополиста (наряду с консерваторами) окончательно закрепилась за мейбористской партией. Итоги парламентских выборов в первом послевоенном десятилетии свидетельствовали об укреплении классичес-

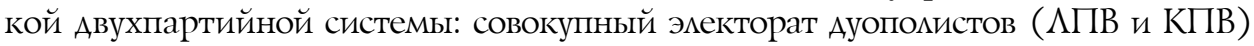
последовательно возрастал (с 84\% в 1945 г. до 96\% в 1955 г.). Выборы 1959 г. положили начало нелинейному, циклическому процессу снижения удельного веса дуополистов на политическом рынке, что сопровождалось соответствующим снижением значений $\mathrm{HHI}$ (рис. 1).

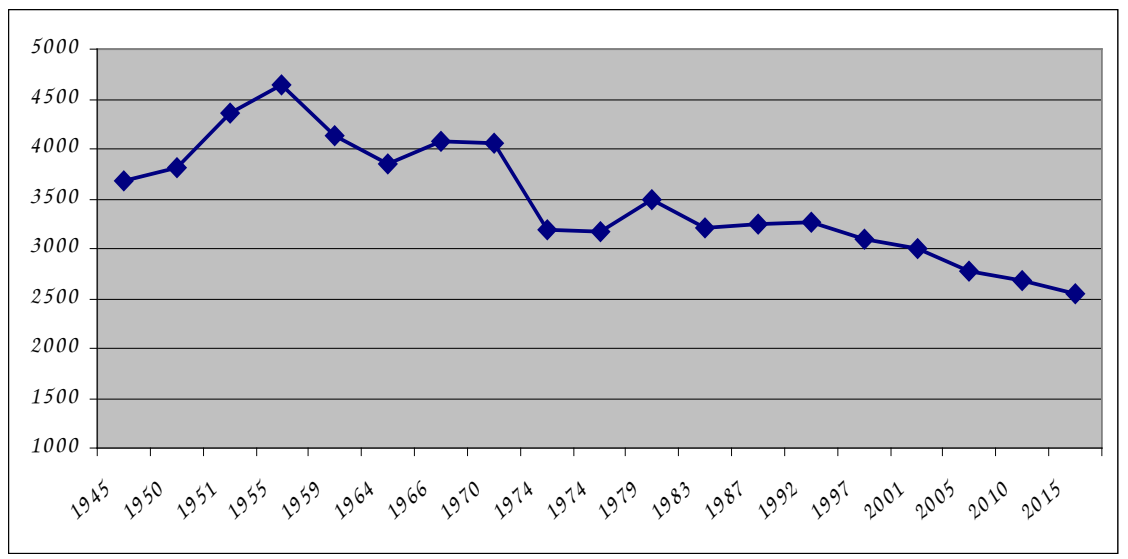

Рис. 1. Аинамика индекса Херфиндаля - Хиршмана (HНI) Аля политического рынка в Великобритании в 1945-2015 гг.

В данном процессе выдемяется резкое падение доли совокупного электората Авух партий-гегемонов по итогам парламентских выборов 1974 г. (сразу на 14,5 проџентных пункта). Аругое резкое падение данного показателя зафиксировано в 1983 г. (на 11 п.п.); оно было вызвано расколом мейбористов и объединением вышеАших из $\Lambda$ П социал-демократов с $\Lambda и$ бералами («черный кризис мейборизма») [3, с. 107]. Количество голосов, поданных за кандидатов «третьей партии» (соџиал-демократов и кибералов) вплотную приблизилось к результатам мейбористов (разрыв всего 2,2 п.п.). Таким образом, можно интерпретировать итоги парламентских выборов 1983 г. как антиџипаџию посмедующего кризиса дуопольного помитического рынка Великобритании. В Аальнейшем по совокупности политических явлений и процессов «эрозия Авухпартийности» продомжилась [4] . Кризис двухпартийной системы в полной мере проявил себя в 2010 г., когАа 
Аоця совокупного эцектората Ауопоцистов Аостигла минимацьного значения (чуть более 65\%), а распределение депутатских мест оказалось таким, что ни одна политическая партия не могла самостоятельно сформировать правительство, и впервые после 1945 г. Вемикобритания получила коациционное правительство (консерваторов и миберальных демократов). Аанный факт поставил исследователей перед вопросом, с чем мы имеем дело: со случайным «техническим сбоем» Авухпартийной системы или с ее полным крахом? [5]. Формирование однопартийного правительства консерваторов по итогам всеобщих выборов 2015 г. еще не является достаточным аргументом в пользу преодоления кризиса дуопоцьного политического рынка Вемикобритании [6]. ПодтвержАением устойчивой тенденџии эрозии Авухпартийной системы также явцяется динамика представитецьства Ауополистов в нижней палате британского парламента. Суммарный относительный показатель в течение полувека варьировался в диапазоне 92-98\%, а начиная с 1997 г. устойчиво держится ниже планки в 90\%. Объяснить это можно периодическими успехами миберальных демократов, укреплением позиций региональных партий (в первую очередь Шотмандской национальной партии), а также взцетом попуцярности Партии независимости Соединенного Королевства (UKIP). ОАнако существующая мажоритарная система, обеспечивающая изрядную политическую ренту победителям, явмяется мощным слерживающим фактором на пути деформации дуопольного политического рынка.

В отличие от Великобритании в Австрии Аействует система пропорционального представительства с относительно невысоким (4\%) проходным барьером. Этот институциональный фактор, очевидно, обусловил (с 1980-х годов) кризис двухпартийной системы, который к настоящему времени закончился разрушением дуопольной системы на автрийском политическом рынке (рис. 2).

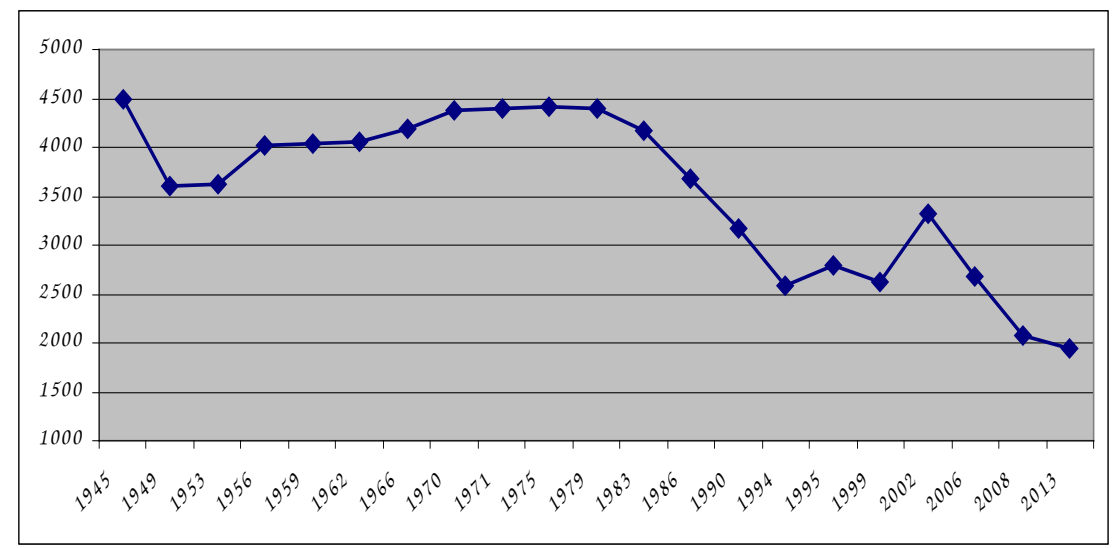

Рис. 2. Аинамика индекса Херфиндамя - Хиршмана (НHI) Аля политического рынка в Австрии в 1945-2013 гг. 
В стремлении сохранить за собой контроль над национальным правительством бывшие Ауополисты избрали стратегию «большой коалиџии», а поле конкуренции за пост федерального президента уступили другим политическим акторам. Таким образом, институциональный фактор может оказывать решающее воздействие на темпы и масштабы роста конкурентности политического рынка.

Исходным отличием политического рынка ФРГ от политического рынка Австрии стал более высокий уровень электоральной конкуренции. Если в Австрии Ауопоцизм политического рынка стац очевиден уже по итогам первых послевоенных парламентских выборов в 1945 г., то в первом составе западногерманского бундестага в 1949 г. кроме партий-гегемонов получили представительство еще восемь избирательных объединений. Процесс консолидации на политическом рынке ФРГ был завершен только к 1961 г., но и тогда сформировалась “Авухсполовинная» партийная система, в которой роль арбитра Аля Авух Аоминирующих политических сил играла «третья партия» - СвАП. Поэтому дмя политического рынка ЗапаАной Германии быма характерна не классическая дуополия, а кишь тенденџия к ней (рис. 3).

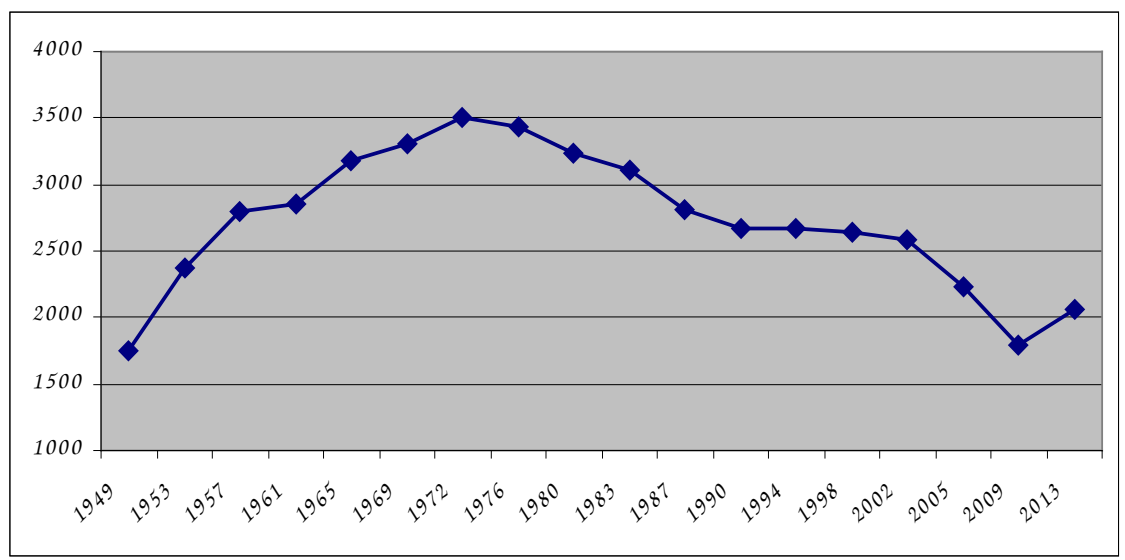

Рис. 3. Аинамика индекса Херфиндамя - Хиршмана (НHI) Аля политического рынка в ФРГ в 1949-2013 гг.

Ретроспективно можно отметить, что трансформация «несовершенной Ауополии» началась в 1983 г., когда в бундестаге утвердица свое преАставительство партия «зеленых». Этот проџесс стал более очевиден после объединения Германии и появления в парламенте фракции Партии демократического социализма (позднее - Мевой партии). Как и в Австрии, дия сохранения контроля наА федеральным правительством «несовершенные дуополисты» на политическом рынке Германии стали придерживаться стратегии «большой коалиции» (ХАС-ХСС + САПГ). СлеАующим этапом реструктуризации помитического рынка ФРГ, по всей видимости, станет увеличение количества партийных фракций в нижней палате федерального парламента за счет «Альтернативы для Германии» и возвращения в бундестаг Свободной Аемократической партии осенью 2017 г. 
Как и в ФРГ, в Ирландии после Второй мировой войны сформировался политический рынок «несовершенной Ауополии» (рис. 4).

Роль «несовершенных дуополистов» традиџионно исполняли правоџентристские партии Фине Гэл (Fine Gael) и Фианна Файц (Fianna Fail). Несовершенность дуополии, как и в ФРГ, проявмялась в том, что крупнейшие партии, как правило, не располагали достаточным парламентским представительством Аля формирования однопартийных правительств и неоднократно прибегали к коалиџии с мевоџентристской мейбористской партией.

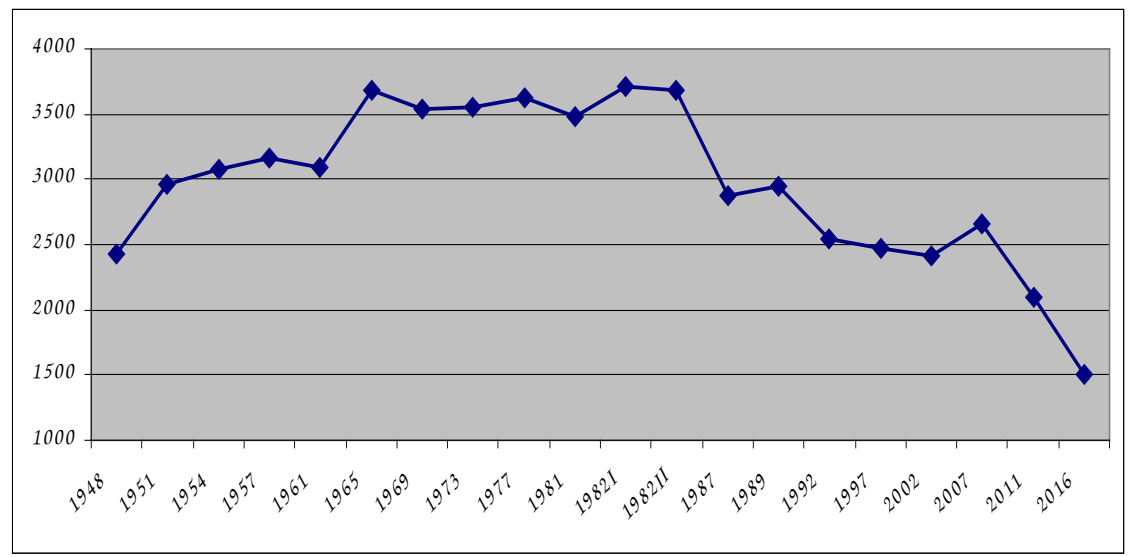

Рис. 4. Аинамика индекса Херфиндаля - Хиршмана (НHI) аля политического рынка в Ирландии в 1948-2016 гт.

Пожалуй, главной институџиональной особенностью ирландского политического рынка явмяется достаточно сложная дмя нашего восприятия система «единого передаваемого голоса» (single transferrable vote, STV) при выборах нижней палаты парламента (Аойл Эрен). В 1980-е годы обозначилась тенденция эрозии «несовершенно дуопольного» политического рынка Ирландии. Аату прошеАших в 2016 г. парламентских выборов ирландские СМИ охарактеризовали как «день малых партий», подчеркнув этим существенный рост их удельного веса в ущерб бывшим «несовершенным Ауополистам».

Тенденции дуополизаџии не обошии стороной и некоторые государства Южной Европы, в которых политические рынки сформировались в начале «третьей волны» демократизации. В качестве примеров проанализируем динамику политических рынков Испании и Греции (рис. 5, 6).

В Испании после постепенного демонтажа франкистского режима в течение нескольких мет сохраняяся переходный периоА консолидации партийной системы, и в результате роль дуополистов утвердилась за «мевой» Испанской социалистической рабочей партией (ИСРП) и «правой» Народной партией. Закрепление гегемонии ИСРП в мевой части партийно-политического спектра происходицо в проџессе серьезной конкурентной борьбы с Компартией и стало возможным благодаря позиџионированию ИСРП как марксистской партии, стоящей намного «мевее» большинства европейских соџиал-демок- 
ратических партий. Неоднократно социалисты и «народники» формировали однопартийные правительства, однако в полном объеме Ауополия на испанском политическом рынке не утвердицась: ведущие партии все чаще стали прибегать к подАержке небольших политических сил Аля укрепления своих правительств [7]. Усимение позиций региональных партий, успешный выхоА на политическую арену новой мевой политической силы (PODEMOS) способствовали разрушению дуополизма и росту конкурентности общенащионального политического рынка. Аестабилизация партийно-политического пространства приводит к Аосрочным парламентским выборам и формированию правительств, не имеющих надежной подАержки в кортесах.

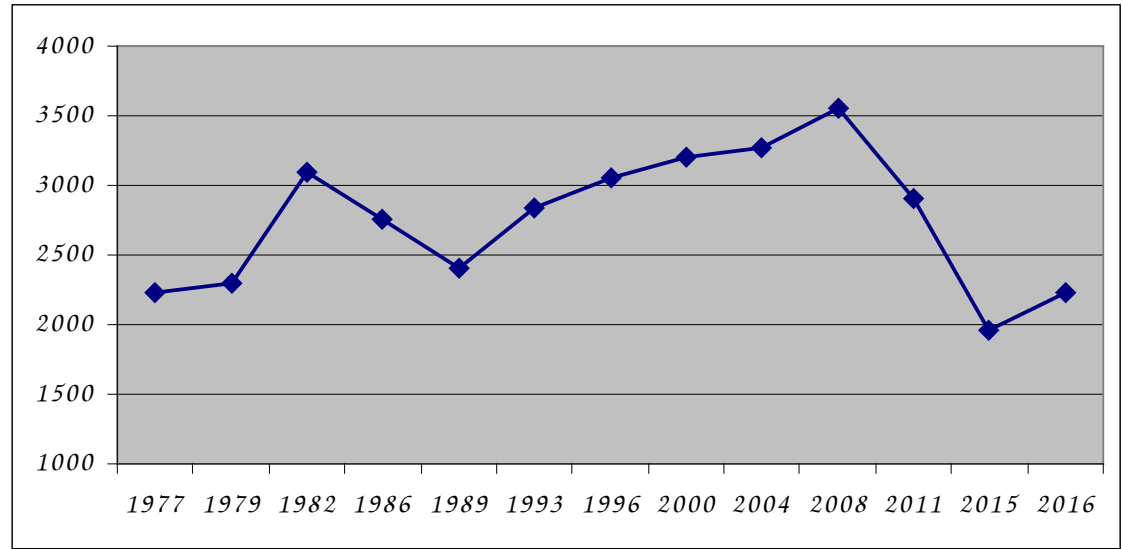

Рис. 5. Аинамика индекса Херфиндаля - Хиршмана (НHI) Аля политического рынка в Испании в 1982-2016 гт.

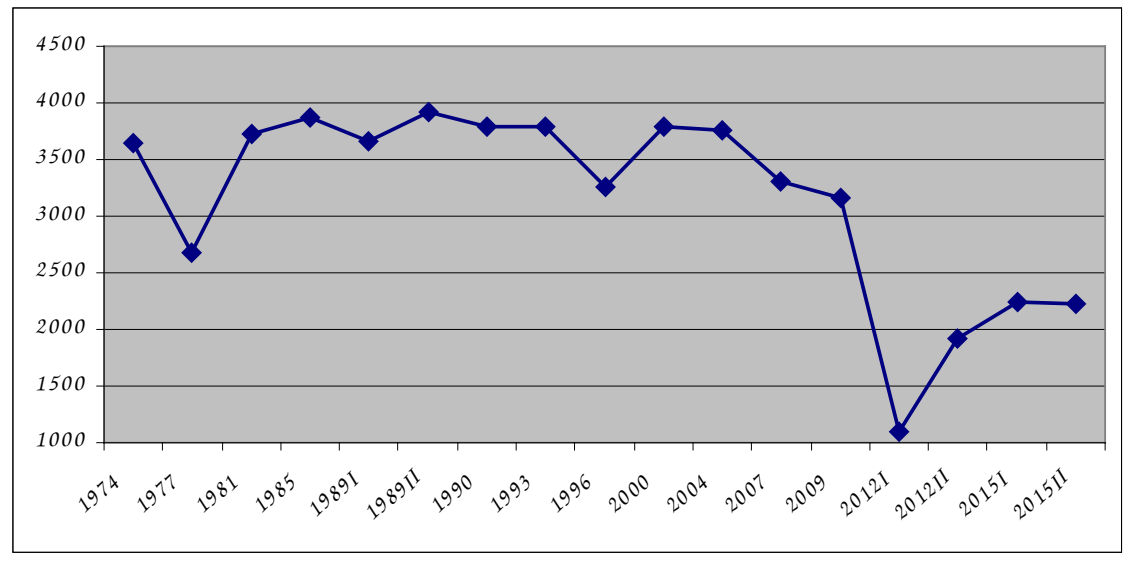

Рис. 6. Аинамика индекса Херфиндамя - Хиршмана (НHI) Аля политического рынка в Греџии в 1977-2015 гг. 
Особенности избирательной системы в Грещии после краха диктатуры «черных полковников» способствовали относительно быстрому формированию Ауопольного политического рынка, приближающемуся к классическому образцу.

Вплоть до начала текущего десятилетия дуополисты - «Новая демократия» и Всегреческое соџиалистическое движение (ПАСОК) - поочереАно формировали однопартийные правительства, опирающиеся на абсолютное парламентское большинство (исключением были очередные и досрочные выборы в 1989 г.). Только острейший соџиально-экономический кризис кардинально изменил партийно-политический мандшафт и привел к миквидаџии дуопоцизма на политическом рынке. В настоящее время наметилась неустойчивая тенденция к формированию рынка «несовершенной дуполии», на котором роль оАного из Ауополистов перешла от ПАСОК к меворадикальной СИРИЗА. Примечательно, что с 2012 г. в Греции формируются правительства на базе открытой «мево-правой» коалиционности.

В проџессе анализа авторы пришии к выводу, что НHI можно использовать Аля оџенки степени конџентраџии (уровня монополизаџии) политических рынков. Наибольшие значения индекса, соответствующие максимальной конџентрации политических рынков, отмечаются в следующих странах: в Великобритании - в 1955 г. (4640,31); Австрии - в 1945 г. $(4498,36)$ и затем в 1975 г. $(4419,76)$; ФРГ - в 1972 г. $(3501,78)$; Ирмандии - в 1965 г. $(3675,9)$ и затем в 1982 г. $(3717,68)$; Испании - в 2008 г. (3548,24); Греции - в 1989 г. (3911,93). Наименьшие значения индекса, соответствующие максимальной фрагментации политических рынков и свидетельствующие о демонтаже дуополизма, отмечаются: в Вемикобритании - в 2015 г. (2544,84); Австрии - в 2013 г. (1937,99); ФРГ - в 2009 г. $(1785,8)$; Ирландии - в 2016 г. (1506,24); Испании в 2015 г. $(1956,47)$; Грещии - в 2012 г. $(1092,92)$.

Аинамика значений ННІ позволяет сделать однозначный вывод о продолжении кризиса дуопольных политических рынков в государствах Западной Европы. Справедливой представмяется точка зрения, согласно которой важными причинами кризиса дуопольных политических рынках явмяются «усияение антиинтеграџионистских настроений в общественном сознании европейџев и укрепление выражающих эти настроения политических сил в партийнополитическом пространстве Евросоюза» [8], выхоА на политическую арену «пиратских партий» как реакщия на углубляющиеся противоречия информационного общества [9] и в целом возникновение политических осей иного характера, нежели основная ось «мевые - правые».

Аинамика значений ННІ позволяет мучше понять тенденџии развития партийно-политических систем тех ици иных государств. Например, динамика значений индекса дмя политического рынка Великобритании свидетельствует о том, что восстановцение однопартийного правления по итогам парламентских выборов 2015 г. вовсе не свидетельствует о «победе Авухпартийности», а напротив, сопровождается усияением ее кризиса. Таким 
образом, на наш взгляд, индекс Херфиндамя - Хиршмана (Herfindahl Hirschman index, HНI) может рассматриваться в качестве полноценного инструмента исследования политического пространства государств в современном мире.

\section{Библиографический список}

1. Холодковский $\kappa$. Перестройка западноевропейской партийной системы // Мировая экономика и международные отношения. 2016. Т. 60, № 7. С. 16-24.

2. Данилов М.В. Исследование российской многопартийности: традиции и инновации. Саратов, 2006.

3. Лидеры современной социал-демократии / под общей ред. В.С. Рыкина. М., 1991.

4. Перегудов C. Великобритания: политические циклы и эрозия двухпартийности // Мировая экономика и международные отношения. 2006. № 3. С. 23-30.

5. Перегудов С.П. Выборы 2010 года в Великобритании: слом двухпартийной системы или очередной сбой? // Мировая экономика и международные отношения. 2010. № 10. С. 12-21.

6. Шеин $C$. Всеобщие выборы в Британии: победа двухпартийности или движение к системе крайнего плюрализма? // Мировая экономика и международные отношения. 2016. Т. 60, № 12. C. 51-61.

7. Хенкин С. Партийно-политическая система Испании на перепутье // Мировая экономика и международные отношения. 2017. Т. 61, № 4. С. 71-80.

8. Вайнштейн Г. Евроскептицизм: новый фактор европейской политики // Мировая экономика и международные отношения. 2015. № 8. С. 40-48.

9. Ровинская T. Политические амбиции европейских «пиратов» // Мировая экономика и международные отношения. 2015. № 7. С. 72-84. 